\title{
Ultrasonographic Imaging of Normal and Impacted Omasum in Indian Crossbred Cows
}

\author{
Sheikh Imran, S. P. Tyagi, Amit Kumar, and Shivali Sharma \\ Department of Veterinary Surgery and Radiology, College of Veterinary and Animal Sciences, Chaudhary Sarwan Kumar Himachal \\ Pradesh Agriculture University, Palampur 176 062, Himachal Pradseh, India
}

Correspondence should be addressed to Sheikh Imran, sheikhimran_08@rediffmail.com

Received 13 January 2011; Revised 27 February 2011; Accepted 28 March 2011

Academic Editor: Mary M. Christopher

Copyright (๑) 2011 Sheikh Imran et al. This is an open access article distributed under the Creative Commons Attribution License, which permits unrestricted use, distribution, and reproduction in any medium, provided the original work is properly cited.

\begin{abstract}
Omasal impaction is a serious disease problem in cattle in India, but it is difficult to diagnose clinically. Ultrasonography has been proposed for the noninvasive evaluation of omasal disease. The objectives of this study were to compare the in vitro and in vivo ultrasonographic appearance of the omasum and to compare omasal appearance, limits, and size in clinically healthy cows with those in cows having confirmed omasal impaction. A $3.5 \mathrm{MHz}$ curvilinear transducer was used to image and record the appearance of the omasum in vitro in a water bath, and its appearance, dorsal and ventral limits, and size in 10 healthy Indian Jersey/Red Sindhi crossbred cows. The results were compared with the ultrasonographic data collected from 5 cows with omasal impaction, as confirmed at necropsy. On moving the transducer dorsoventrally in each intercostal space and below the costal arch, the wall of omasum could be seen as an echogenic arc-like structure. The difference between mean dorsoventral extents of the normal and impacted omasums was statistically insignificant. These results suggest that ultrasonographic imaging may not be useful in the diagnosis of omasal impaction in Indian crossbred cows, however, additional studies may be warranted.
\end{abstract}

\section{Introduction}

The omasum is not easily accessible for clinical examination by palpation, percussion, or auscultation because of its topographic location under the costal part of the abdominal wall [1]. It can neither be examined by rectal palpation nor radiographed, thus making the diagnosis of omasal conditions very difficult. The omasum is also affected by other disorders of the gastrointestinal tract, such as reticuloomasal stenosis, traumatic reticuloperitonitis, abomasal displacement/volvulus, pyloric stenosis, and ileus [2].

Omasal impaction is reported in cattle living in tropical climates mostly secondary to ruminal impaction as a result of poor quality tough and fibrous feeds [3, 4]. Since the introduction of machine-made wheat straw feeding in India, omasal impaction has gained great importance because such straw is poorly digestible and light in weight, which leads to excessive consumption [3]. Clinical signs of the disease are vague and include anorexia, constipation, dullness, ruminal distension, dehydration, congested mucous membranes, and reduced milk yield [3-5]. Exploratory laparotomy can be used to confirm a diagnosis of omasal impaction, however its invasiveness may not be suitable in already compromised patients. Ultrasonography has been proposed as a noninvasive and helpful method for subjective assessment of the normal and impacted omasum in cows and buffaloes $[6,7]$. The purpose of the present study was to describe observations based on ultrasonographic examination of the omasum in an organ bath and in healthy Indian Jersey/Red Sindhi crossbred cows and to compare these results with the ultrasonographic findings in cows having omasal impaction.

\section{Materials and Methods}

2.1. Organ Bath Study. The omasums were collected from 3 cows that were euthanized at the teaching veterinary clinical complex, Chaudhary Sarwan Kumar Himachal Pradesh Krishi Vishvavidalaya (CSKHPKV), Palampur for disorders unrelated to thoraco-abdominal disease. The apparently normal omasums were collected within 3 hours after death. Initially, the whole omasum was immersed in the water bath, however, layering of the omasal wall and omasal laminae could be visualized only after the contents were evacuated. 
Thus, only cut portions of the omasal wall were immersed and examined in the water bath. A $3.5 \mathrm{MHz}$ curvilinear transducer secured in a water-tight gel-laden polythene covering was used for imaging.

2.2. Ultrasonography of the Omasum in Healthy Cows. Ultrasonographic examinations were performed on 10 adult, nonpregnant, crossbred Jersey/Red Sindhi cows. The cows were considered to be clinically healthy based on the results of routine physical examination and a complete blood count (CBC). The cows were between 4-12 years old and weighed approximately $300-450 \mathrm{~kg}$. The area extending from the tuber-coxae to the 5th intercostal space and from the dorsal midline to the linea alba on right side was shaved. Animals were secured in a standing position in a cattle crate without chemical restraint. The omasum and adjacent organs were examined with a $3.5 \mathrm{MHz}$ curvilinear transducer. The distances between the dorsal midline and the dorsal and ventral ultrasonographic margins of the omasum were measured from the 11 th to 7 th intercostal spaces (Figure 1 ).

2.3. Clinicopathological Findings and Ultrasonography of Cows with Omasal Impaction. Five Jersey/Red Sindhi crossbred adult cows with omasal impaction were evaluated ultrasonographically for comparison with the clinically healthy cows. The cows were referred to the Department of Veterinary Surgery and Radiology, CSKHPKV Agricultural University, Palampur for evaluation of suspected forestomach disorders. Clinical signs, present from 4-7 days prior to referral, included dullness, dry muzzle and sunken eyes, increased respiratory and heart rates, and subnormal rectal temperature. Abdominal auscultation revealed borborygmi in 2 of the 5 cows. On rectal examination, fecal material was absent and the rectal mucosa was dry. One cow had signs of colic. The results of a CBC included polycythemia, leukocytosis with mature neutrophilia, and lymphopenia, consistent with dehydration and stress. Ultrasonography was performed in a manner similar to that of the healthy cows. Exploratory laparotomy was done in 2 cows, which revealed the omasum as a hard elongated ball on palpation consistent with omasal impaction, and peritoneal effusion was also noted.

The cows died during the course of treatment, within 4-5 days of admission, and routine necropsy was performed. All cows had severe omasal impaction with tightly bound dry flaky ingesta (Figure 2); the gastrointestinal tract distal to the omasum was empty. The omasal laminae were friable and the mucosa was ulcerated and congested. Abomasal erosions and ulcerations were seen in all cows and were more severe in the cow with signs of colic.

2.4. Statistical Analysis. The mean $\pm \mathrm{SD}$ of the measurements were calculated and unpaired two-tailed $t$-tests were used to compare the results between clinically healthy cows and cows with omasal impaction (GraphPad Software, http://www.graphpad.com/quickcalcs/ttest2.cfm). A $P$-value of .05 was considered as statistically significant, assuming the conventional alpha level of .05. $P$-value greater than .05 did not reject the null hypothesis (same mean dorso-ventral

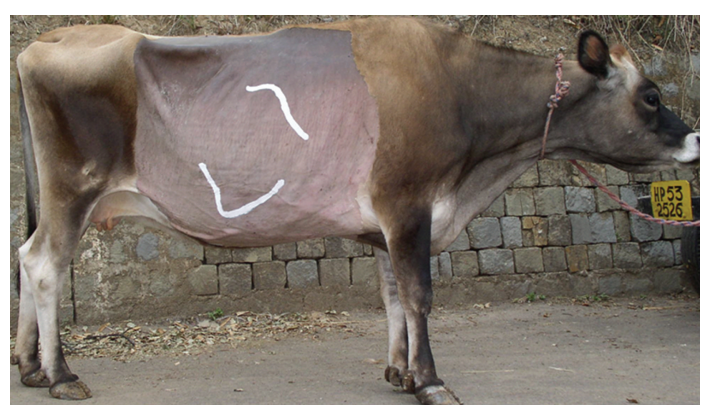

FIGURE 1: Ultrasonographic topography of the omasum depicting the dorso-ventral and craniocaudal extents over the right hemiabdomen of a clinically healthy Indian Jersey/Red Sindhi cow.

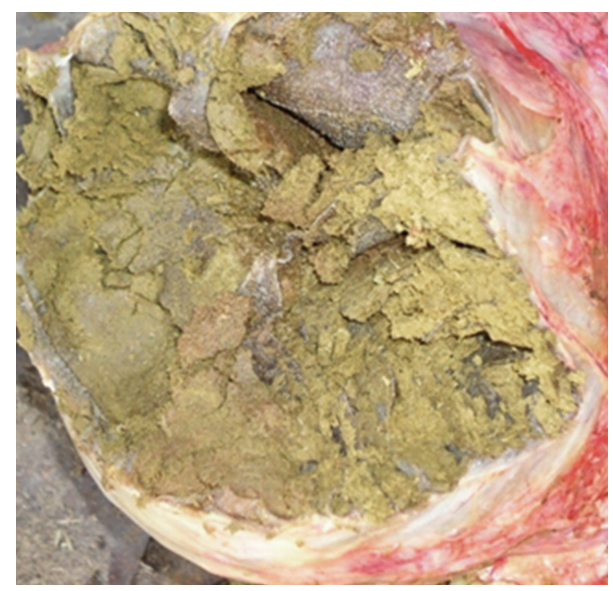

Figure 2: Postmortem view of the omasum in a cow with omasal impaction, packed with dry, firm ingesta.

extents of omasum in normal and impacted cows) and the difference was considered to be statistically not significant.

\section{Results}

3.1. Organ Bath Study. The omasal wall adjacent to the transducer had an outer thin echogenic tunica serosa/subserosa and inner thick echogenic tunica mucosa separated by a thin middle hypoechogenic tunica muscularis. Multiple echogenic mucosal laminae attached to the tunica mucosa could also be seen undulating in the water bath (Figure 3 ).

\subsection{Ultrasonography of the Omasum in Healthy Cows. The} wall of the omasum could be seen as an echogenic arc by moving the transducer dorsoventrally in the 7 th to 11 th intercostal spaces and below the costal arch in all the cows, and in the 6th intercostal space in 4 cows (Figures 4 and 5). More cranially in the 6 th intercostal space, the omasum could be differentiated from the reticulum with certainty only by the biphasic motility of the later. Omasal contents could not be visualized in any of the cows. In 3 cows, echogenic streaks originating from the omasal wall were interpreted as mucosal laminae. Layering of the wall of the omasum, similar to that seen in the organ bath study, was seen in 2 cows, with the echogenic tunica serosa and mucosa separated by a thin 


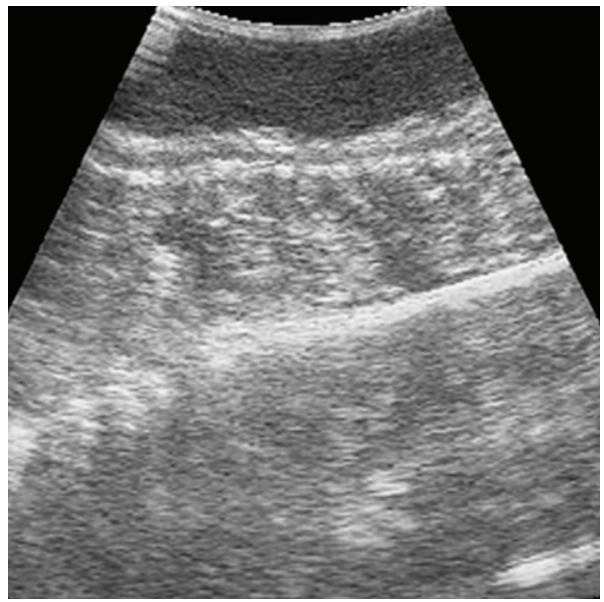

(a)

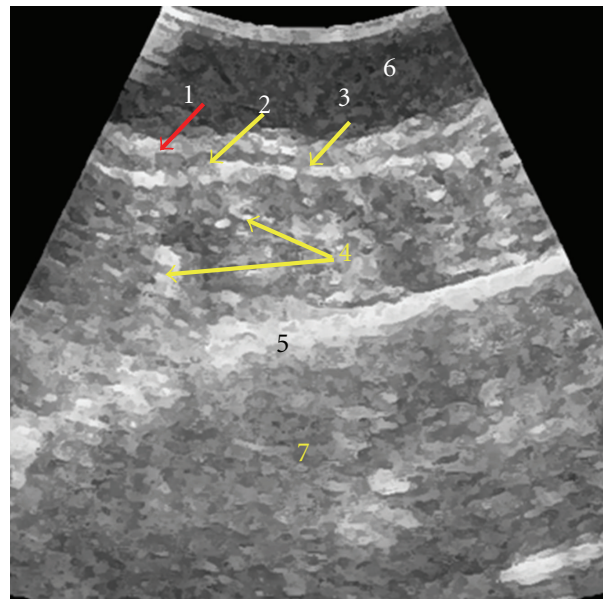

(b)

FIGURE 3: Ultrasonographic appearance of omasum in a water bath. (1) Tunica serosa, (2) tunica muscularis, (3) tunica mucosa, (4) omasal laminae, (5) base of the plastic container. (6) Water, (7) mirror-image artifact.

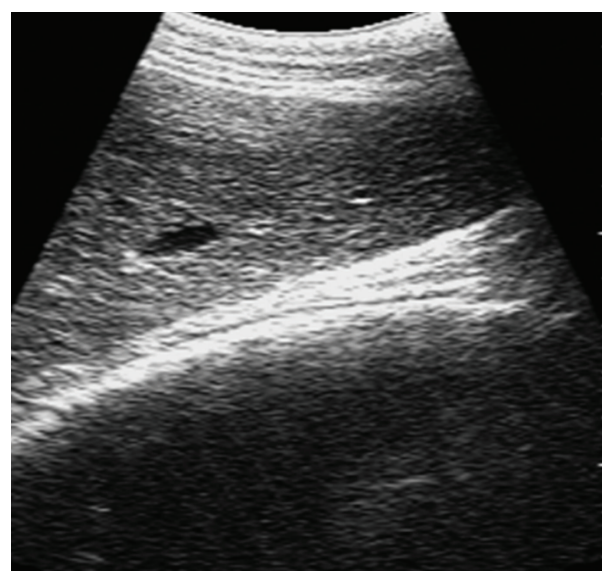

(a)

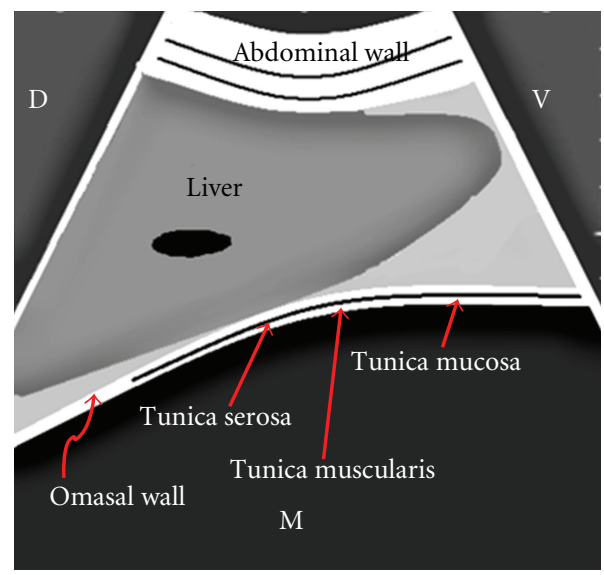

(b)

FIGURE 4: Ultrasonogram of the omasum and liver in a clinically healthy cow, obtained at the 10th intercostal space by placing the transducer parallel to ribs. $\mathrm{D}=$ dorsal, $\mathrm{V}=$ ventral, $\mathrm{M}=$ medial.

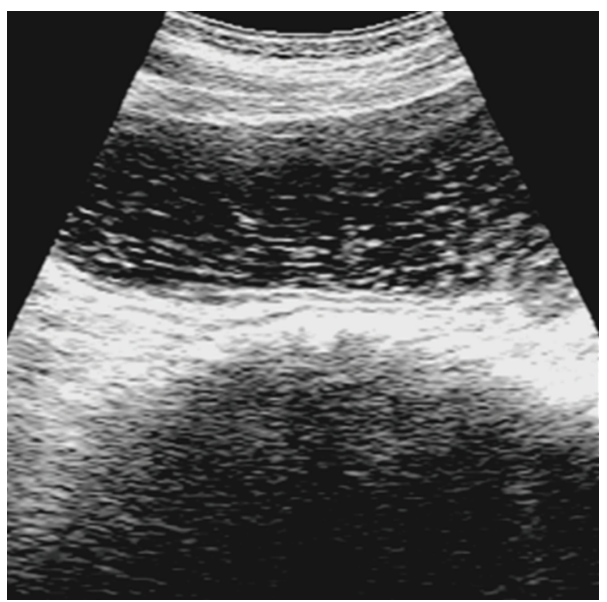

(a)

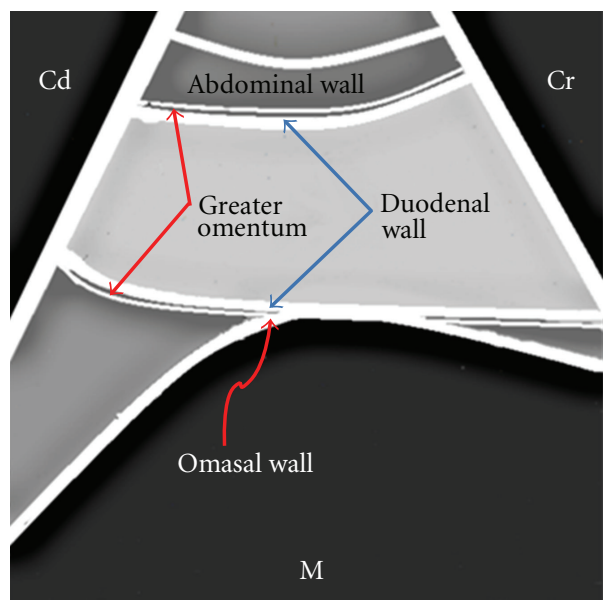

(b)

Figure 5: Ultrasonogram of the cranial duodenum and omasum in a clinically healthy cow, obtained by placing the transducer just ventral to the costal arch of the 8th to 9 th intercostal spaces and parallel to the longitudinal axis of the cow. $\mathrm{Cr}=\mathrm{cranial}, \mathrm{Cd}=\mathrm{caudal}, \mathrm{M}=\mathrm{medial}$. 
TABLE 1: The size and extent of omasal margins as measured ultrasonographically in the 7th to 11th intercostal spaces of clinically healthy cows and cows with omasal impaction.

\begin{tabular}{|c|c|c|c|c|c|c|}
\hline Group & \multicolumn{6}{|c|}{ Measurement $(\mathrm{cm})$ in each intercostal space indicated as mean $\pm \mathrm{SD},($ minimum-maximum $)$} \\
\hline \multirow{6}{*}{$\begin{array}{l}\text { Healthy cows } \\
(n=10)\end{array}$} & \multirow{3}{*}{ Dorsal margin } & 11th & 10th & 9th & 8th & 7th \\
\hline & & $30.3 \pm 2.31$ & $31.3 \pm 2.75$ & $37.5 \pm 3.14$ & $43.9 \pm 2.95$ & $50.3 \pm 3.49$ \\
\hline & & $(25.3-35.3)$ & $(26.2-35.4)$ & $(29.69-41.32)$ & $(37.5-48.8)$ & $(42.4-56.7)$ \\
\hline & \multirow{2}{*}{ Ventral margin } & $55.3 \pm 3.44$ & $61.8 \pm 3.13$ & $68.6 \pm 3.53$ & $59.4 \pm 3.2$ & $61 \pm 3.73$ \\
\hline & & $(45.5-58.2)$ & $(56.4-72.6)$ & $(60.3-79.5)$ & $(54.4-64.8)$ & $(56.6-63.3)$ \\
\hline & Mean dorso-ventral extent ${ }^{\S}$ & 25.0 & 30.5 & 31.1 & 15.5 & 10.7 \\
\hline \multirow{5}{*}{$\begin{array}{l}\text { Cows with omasal } \\
\text { impaction }(n=5)\end{array}$} & \multirow{2}{*}{ Dorsal margin } & $32.14 \pm 2.84$ & $32.22 \pm 2.63$ & $38.32 \pm 2.89$ & $42.46 \pm 2.62$ & $52.21 \pm 2.49$ \\
\hline & & $(26.2-36.3)$ & $(26.1-36.4)$ & $(28.8-42.7)$ & $(34.4-46.2)$ & $(45.4-55.3)$ \\
\hline & \multirow{2}{*}{ Ventral margin } & $54.18 \pm 2.97$ & $62.43 \pm 2.51$ & $70.43 \pm 2.66$ & $60.31 \pm 2.83$ & $62.26 \pm 2.73$ \\
\hline & & $(46.7-56.3)$ & $(56.8-73.9)$ & $(59.8-77.4)$ & $(52.1-66.3)$ & $(57.3-64.5)$ \\
\hline & Mean dorso-ventral extent ${ }^{\S}$ & 22.0 & 30.2 & 32.1 & 17.8 & 10.1 \\
\hline
\end{tabular}

${ }^{\S}$ Significant differences were not observed in the results from cows with omasal impaction compared with healthy cows $(P>.05$, unpaired $t$-test).

hypoechogenic tunica muscularis. No active contractions of the omasal wall were observed in any cow even after placing the transducer at same site for about 5 minutes. However, slight changes in the shape of the omasal wall synchronous with respiratory movements were occasionally seen. Other organs seen adjacent to the omasum were the ventral liver lobe, gall bladder, cranial part of the duodenum, loops of jejunum, and reticulum. The distance from dorsal midline to omasal margins and dorso-ventral extent of the omasum were tabulated (Table 1). The dorsal and ventral limits of the omasum formed roughly a convex and concave arc, respectively.

\subsection{Ultrasonography of the Cows with Omasal Impaction.} The mean dorsoventral extents (11th-7th ICS) of the impacted omasums were not statistically significantly different from the values obtained in the healthy cows $(P=.9838)$. Biphasic reticular motility was absent in 3 cows, and its amplitude was greatly reduced in 2 cows. No ultrasonographic changes were seen in the abomasum and liver parenchyma, but moderate to severe distension of the gallbladder was observed in all cows. The loops of jejunum were 1.9 to $2.6 \mathrm{~cm}$ in diameter (mean $\pm \mathrm{SD}, 2.4 \pm 0.64 \mathrm{~cm}$ ). Varying amounts of hypo- to anechogenic content were observed within the intestinal lumen of all cows, and anechogenic fluid was interspersed with intestinal loops in 2 cows. Peristalsis was mild in 3 cows and absent in 2 cows.

\section{Discussion}

Ultrasonographic examinations of the omasum were straightforward in all the healthy cows. The omasum was easily identified because of its location immediately adjacent to the costal part of the right abdominal wall. The attachments of the omasal laminae were only occasionally visible in healthy cows, however the laminae were visible as wave like lines in the organ bath study. Based on similar findings in the two groups of cows, ultrasonography was not helpful in the diagnosis of omasal impaction.

The layering of the wall of the omasum as seen in the organ bath study was similar to previously reported findings [6], however, these details were observed in organ bath in only 2 healthy cows. Ultrasound waves are attenuated while traversing the thoracic wall and omasal contents, which likely resulted in the poor detail of the omasal wall and underlying structures in live animals, compared with the acoustic enhancement of details by water in the organ bath. Braun and Blessing [8] described the omasum in 30 clinically healthy Swiss Braunvieh cows as an echogenic crescent in which only the portion of the wall closest to the transducer could be visualized due to acoustic shadowing of the gas-wall interface.

Motility of the omasum was not observed in any of the cows in the present study, consistent with previous studies that suggested the omasum does not have active motility of its own, unlike the reticulum, although slight synchronous changes in omasal position are seen in association with respiratory movements [8]. However, contractions of the omasum, with a reduction in its size, were reported in cows in another study, and a lack of motility was considered to be indicative of omasal impaction [6]. Lack of omasal motility in healthy cows in the present study, even after 5 minutes of observation, does not support the use of this parameter as an indicator of impaction.

The omasum was visualized in the 11th to 7 th intercostal spaces (and occasionally the 6th intercostal space) in the cows in this study and in the study by Braun and Blessing [8]; however, in the study by Mohindroo et al. [6], the omasum was visualized in the 8th to 9th intercostal space and a caudocranial limit beyond the 8th to 9th intercostal space was 
taken as definitive indication of omasal enlargement due to impaction. In addition, visualization of the dorsal limit of the omasum up to middle third of the rib cage and the ventral limit up to the ventral midline also was interpreted as omasal enlargement. In our study, these size variations were observed in clinically healthy cows. In addition, distention of the omasum, with expanded ultrasonographic dorsoventral and caudocranial limits was found in intestinal intussusception in cows [9]. Further, dorsal displacement of the liver due to a distended omasum, as seen in cases of intestinal intussusception, was also not observed. Therefore, the omasal distention based on subjective evaluation cannot be considered as an invariable indicator of omasal impaction.

The quantitative results of our study were slightly lower than those obtained by Braun and Blessing for clinically healthy Swiss Braunvieh cows [6], likely due to differences in breed- and body weight-based variation in the dorsoventral extent of the omasum. Normalization of these parameters based on cow size would be a useful way to compare studies and develop criteria that could be applied to cows of different breeds and body weights.

Prominent distal anechoic acoustic shadow of the impacted feed material has been considered as diagnostically significant [6, 7]. However, in our study, distal acoustic shadow could not be observed in any of the cases of omasal impaction.

Although jejunal diameter was not measured in the clinically healthy cows in the present study, jejunal diameter in 10 clinically healthy Indian Jersey/Red Sindhi crossbred cows in another study, determined by ultrasonography, ranged from 2.1 to $3.6 \mathrm{~cm}$ (mean, $3.1 \mathrm{~cm}$ ) [10], suggesting that decreased diameter of the jejunal loops might be associated with the omasal impaction. This could result from proximal outflow obstruction at the omasoabomasal orifice, leading to gradual emptying of the distal gastrointestinal tract, as was seen at necropsy. Further study of ultrasonographic findings in the jejunum is warranted in cows with omasal impaction and other gastrointestinal diseases.

The cause of abomasal ulcers in the cows with omasal impaction was unknown, and they were not identified ultrasonographically. Braun et al. [11] also were unable to detect abomasitis or abomasal erosions/ulcers by ultrasound in 16 cows and attributed this to the small size of the ulcers and the low resolution of a $3.5 \mathrm{MHz}$ transducer.

In conclusion, although the number of animals in this study was low, no characteristic differences were found in the ultrasonographic appearance, limits, and size of the omasum in cows with omasal impaction compared with clinically healthy cows.

Therefore, ultrasound may have limited application in diagnosing this disorder. Preliminary evidence exists for reduced diameter and motility of jejunal loops, however additional studies are needed to further evaluate this.

\section{References}

[1] G. Dirksen, "Digestive system," in Clinical Examination of Cattle, G. Rosenberger, G. Dirksen, H. D. Grunder, E. Grunert,
D. Krause, and M. Stober, Eds., pp. 218-220, Paul Parey, Hamburg, Germany, 2nd edition, 1979.

[2] U. Braun, S. Blessing, B. Lejeune, and M. Hässig, "Ultrasonography of the omasum in cows with various gastrointestinal diseases," Veterinary Record, vol. 160, no. 25, pp. 865-869, 2007.

[3] S. Turkar and S. K. Uppal, "Blood biochemical and ruminal liquor profile in buffaloes (Bubalus bubalis) showing omasal impaction," Veterinary Research Communications, vol. 31, no. 8, pp. 967-975, 2007.

[4] J. Singh, A. P. Singh, and D. B. Patil, "Digestive system," in Ruminant Surgery, R. P. S. Tyagi and J. Singh, Eds., pp. 203204, CBS Publishers, Delhi, India, 1st edition, 1993.

[5] T. Umakanthan, "Native drug therapy for omasal impaction in cattle," Indian Veterinary Journal, vol. 79, no. 3, pp. 295-296, 2002.

[6] J. Mohindroo, A. Kumar, V. Sangwan, R. Udehiya, and S. S. Singh, "Ultrasonographic evaluation of the omasum in cows and buffaloes," Veterinary Radiology and Ultrasound, vol. 49, no. 3, pp. 295-299, 2008.

[7] H. Athar, J. Mohindroo, K. Singh, A. Kumar, and T. Singh, "Ultrasonographic features of omasal impaction in bovines," Indian Journal of Veterinary Surgery, vol. 30, pp. 115-116, 2009.

[8] U. Braun and S. Blessing, "Ultrasonographic examination of the omasum in 30 healthy cows," Veterinary Record, vol. 159, no. 24, pp. 812-815, 2006.

[9] S. Imran, S. P. Tyagi, A. Kumar, K. Amit, A. Sharma, and S. Sharma, "Usefulness and limitation of ultrasonography in the diagnosis of intestinal intussusception in cows," Veterinary Medicine International, vol. 2011, Article ID 584387, 2011.

[10] S Imran, Ultrasonography of bovine abdominal cavity, M.S. thesis, CSK Himachal Pradesh Krishi Vishvavidyalaya, India, 2010.

[11] U. Braun, K. Wild, and F. Guscetti, "Ultrasonographic examination of the abomasum of 50 cows," Veterinary Record, vol. 140, no. 4, pp. 93-98, 1997. 

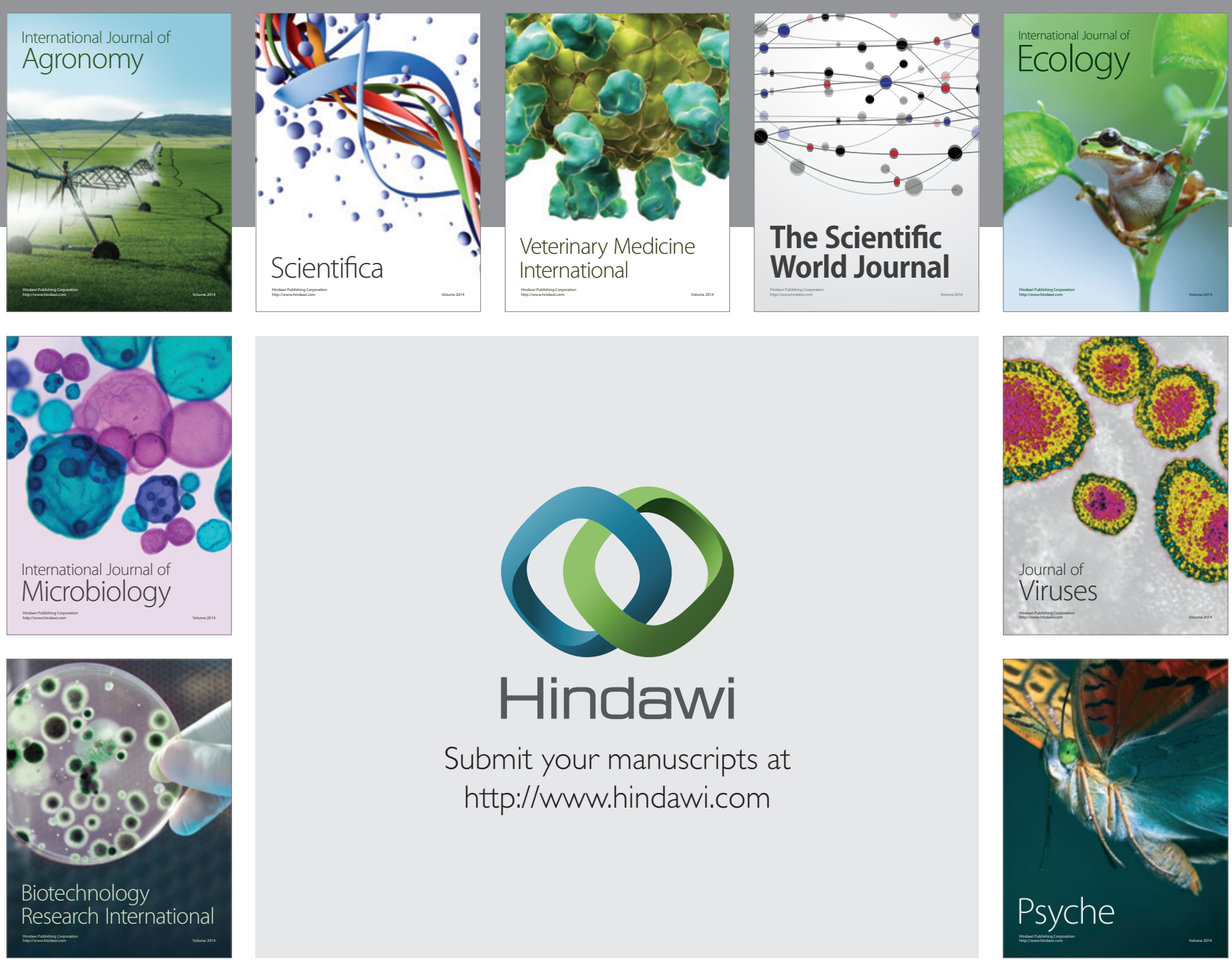

Submit your manuscripts at

http://www.hindawi.com
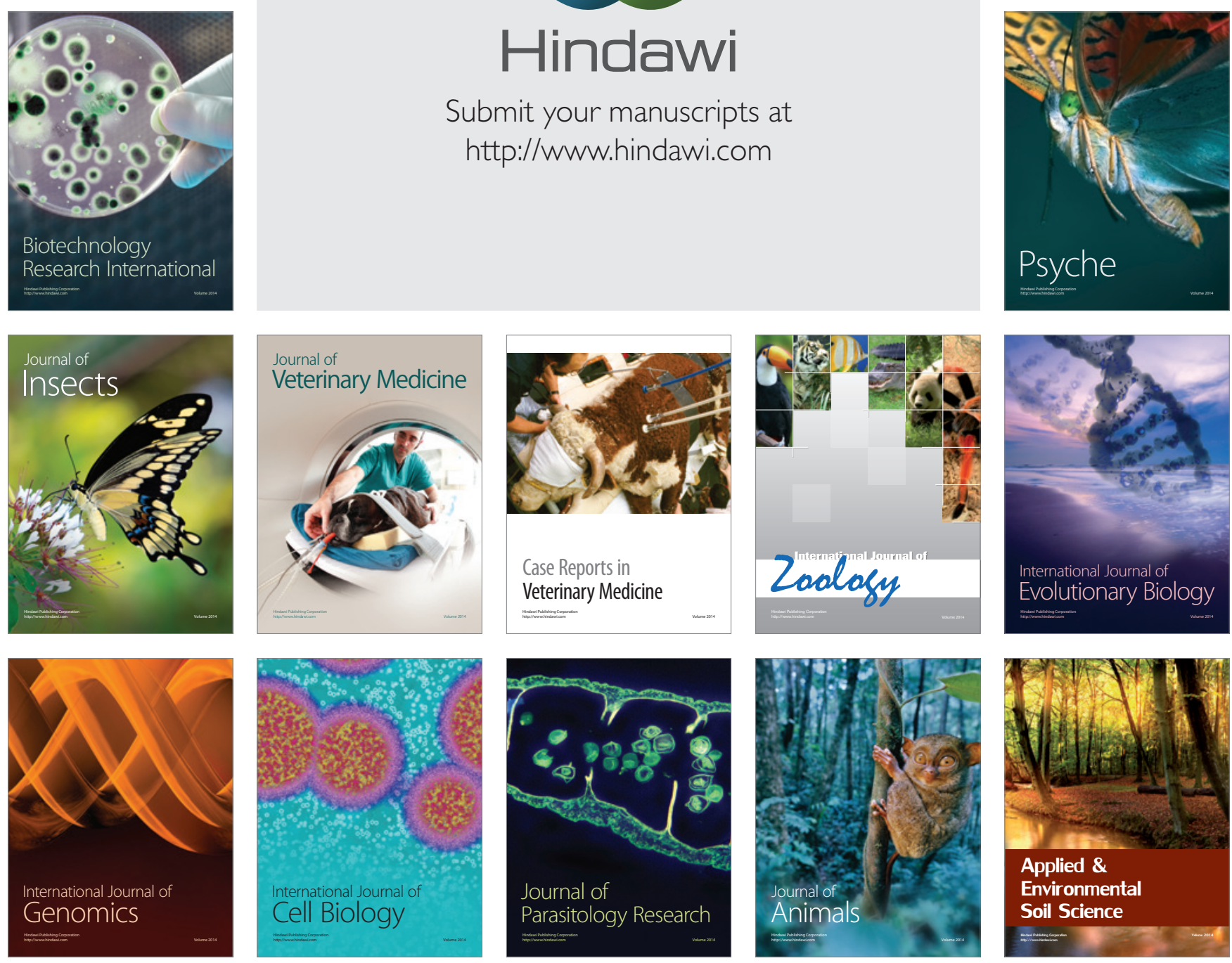